\title{
SHANGAI QUER SABER O QUE O FILME TEM A DIZER
}

\author{
Luciana Martha Silveira ${ }^{1}$
}

Shangai não é mais somente uma cidade da China. Shangai não é mais somente um lugar. Shangai também é o nome de uma exposição de fotografias do grupo Baita Profissional, que o MusA, Museu de Arte da Universidade Federal do Paraná (UFPR) acolheu em Curitiba, de 28 de janeiro a 04 de abril de 2014.

Trata-se de um grupo gaúcho de fotógrafos, que resolveu explorar uma ideia instigante, de tom bem-humorado, desafiador e, porque não dizer, interventor.

Em plena hegemonia da câmera digital, onde se percebe o elogio à rapidez, ao disparar automático de um botão, à segurança de uma edição posterior, à transparência do aparelho fotográfico, este grupo se juntou para fazer valer o slow motion da captura, o prazer da escolha e o frio-na-barriga da edição online.

As fotografias expostas foram geradas a partir de um filme em preto-e-branco made in China, de qualidade duvidosa e marca desconhecida dos fotógrafos. Com essa interferência, isto é, com a mediação de um filme em que não se pode confiar, o processo começa.

É interessante pensar que a escolha deste filme para mediar a captura das imagens acaba interferindo na intenção primeira dos fotógrafos. O slow motion da captura, o prazer da escolha e a ansiedade da edição online fica claramente dividido entre o fotógrafo e o filme. Diante da qualidade duvidosa do filme, entra em cheque a captura da imagem e se o resultado vai fazer jus à escolha.

Com isso, o frio-na-barriga aumenta, pois deste filme também vai depender a "boa fotografia". Sabemos que não se pode vincular a fotografia à necessidade de um referente, pois ela pode existir sem ele, porém, a câmera, a luz, o diafragma, o obturador, o "filme", tudo isso é necessário para a aparição da imagem fotográfica (Machado, 1984).

$\mathrm{O}$ resultado da exposição são imagens lindas, cativantes, instigantes. Imagens produzidas por, no mínimo, dois autores. Digo no mínimo porque, com o filme evidente, criou-se o convite ao espectador para fazer parte da autoria, compondo as imagens com sua crítica, e também sua

\footnotetext{
${ }^{1}$ Universidade Tecnológica Federal do Paraná, Brasil.
}

Iluminuras, Porto Alegre, v. 15, n. 35, p. 403-410, jan./jul. 2014 
história. O prazer extrapola a captura da imagem para o prazer de perceber a mediação, a possibilidade de se desfazer de um desnecessário controle absoluto, gerando bom humor e diversão.

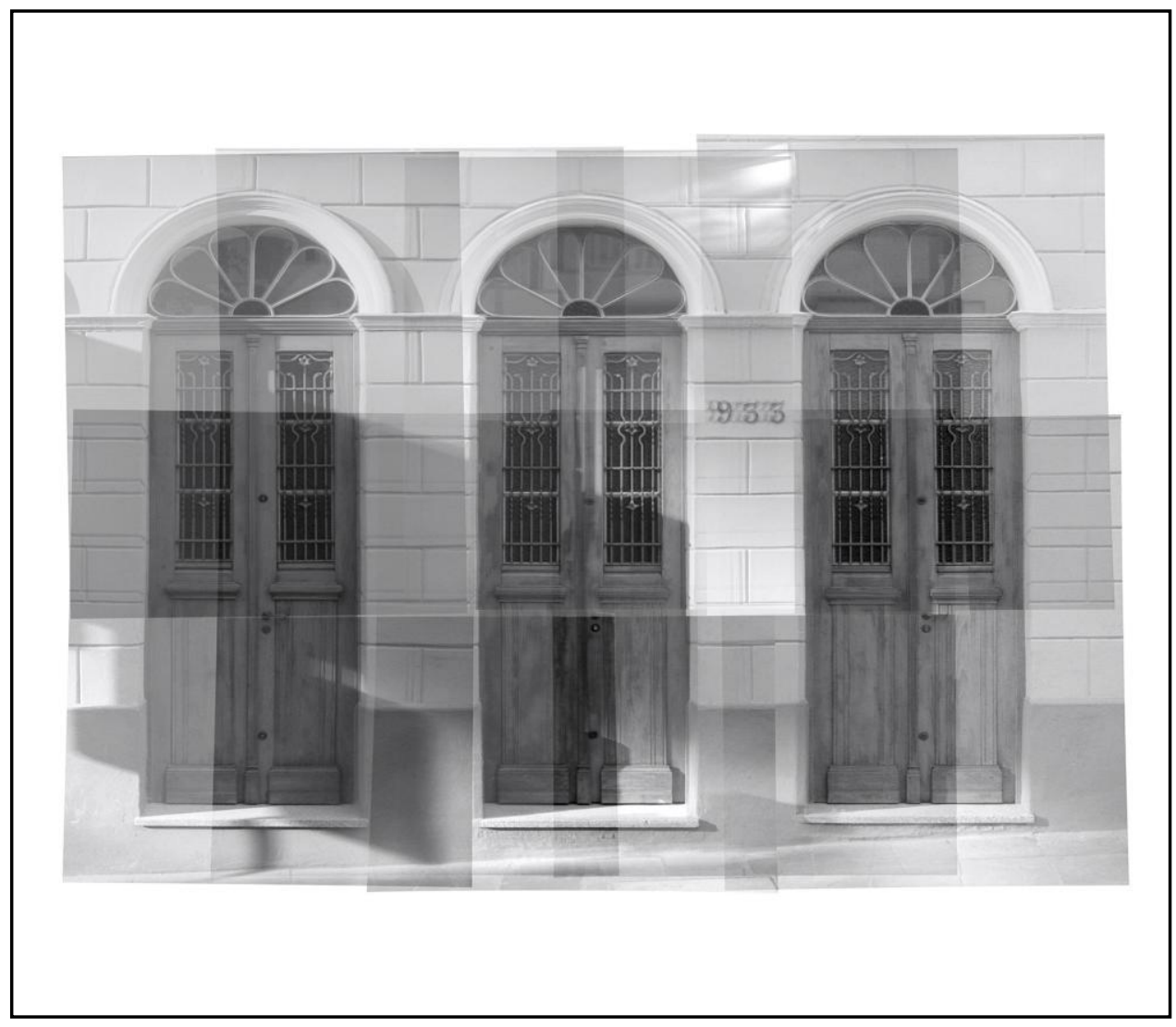

Figura 1: Imagem fotográfica exibida na exposição "Shangai”, de Fabrício Barreto, Curitiba 2014.

Extrapolando um pouco mais a ideia de bom humor, desafio e intervenção, sigo com meus comentários passeando em Shangai.

De onde vem o bom humor? De onde vem a diversão? De onde vem o prazer? Porque pensar em se divertir na captura de imagens fotográficas se é um processo tão sério? Porque pensar em se divertir na apreciação de uma obra de arte? O bom humor vem dos fotógrafos e contagia os espectadores.

Iluminuras, Porto Alegre, v. 15, n. 35, p. 403-409, jan./jul. 2014 
Dos fotógrafos, autores em Shangai, a diversão, o bom humor e o prazer vêm, por um lado, pela brincadeira de capturar as imagens sem ter a certeza (e nem a obrigação, viva!) de produzir uma imagem perfeita, "padrão fotografia”. O prazer está em deixar os olhos passearem e confiar plenamente na sua sensibilidade para capturar a imagem. Um deleite, um verdadeiro deleite.

Por outro lado, está no prazer de capturar as imagens uma a uma, devagar, pensando na quantidade de exposições que se tem. A finitude do número de exposições do filme é um jogo, uma brincadeira, um prazer.

Para os fotógrafos é quase uma obrigação produzir imagens perfeitas. Uma obrigação construída historicamente pela gênese automática da fotografia.

A discussão sobre as relações entre a máquina e o fotógrafo existe desde o século XIX, mas foi a partir do séc. XX que a fotografia se firmou como tecnologia básica para a maioria das mídias, como sendo a imagem "perfeita” que se deve buscar a qualquer custo (Silveira, 2002).

Atualmente, com a imagem digital substituindo a imagem analógica tão fortemente, a discussão no entorno da fotografia continua fixando-se fundamentalmente na sensação de verossimilhança causada pela imagem fotográfica em relação aos objetos, pessoas ou cenas registradas e também no grau de interferência da gênese mecânica dentro do processo de captura da imagem.

Diferentemente da escrita ou da pintura, onde os autores parecem interferir mais diretamente no processo de representação do real, a fotografia provoca a sensação de testemunho da realidade. Isso se deve à sua gênese mecânica, que ilusoriamente eliminaria o homem do processo de captação da imagem. A esta relação dá-se o nome de mimese (Dubois, 1998).

Paralelamente à mimese, existem discursos contrários à ideia de reprodução automática e “fiel” do real pela fotografia. São os chamados discursos desconstrutores.

Os discursos desconstrutores pensam a fotografia interpretando e transformando a realidade, colocando a gênese automática da imagem fotográfica na situação de análise, interpretação e interferência ideológica na reprodução do real.

Alguns autores elegem argumentos para mostrar que a fotografia não pode ser espelho perfeito do real. Consideram como "falhas" na representação pictórica a redução da tridimensionalidade do mundo à bidimensionalidade, a eliminação pela fotografia de qualquer informação (sonora, tátil, gustativa, olfativa) que não pode ser convertida em termos ópticos, o caráter estático que congela o instante, a alteração do cromatismo da cena real tanto na fotografia

Iluminuras, Porto Alegre, v. 15, n. 35, p. 403-409, jan./jul. 2014 
em preto-e-branco quanto na colorida, o espaço eleito pelo enquadramento inevitável da máquina fotográfica e finalmente a granulação da imagem. Estas seriam então, transformações que a cena real sofreria ao atravessar a máquina fotográfica para se fixar em um suporte.

O que era "simples" e "mínima" intervenção do operador da câmera na mimese, (o recorte, o enquadramento ou a escolha do tema), pelo discurso da desconstrução denuncia a presença humana de interferência num processo considerado "automático".

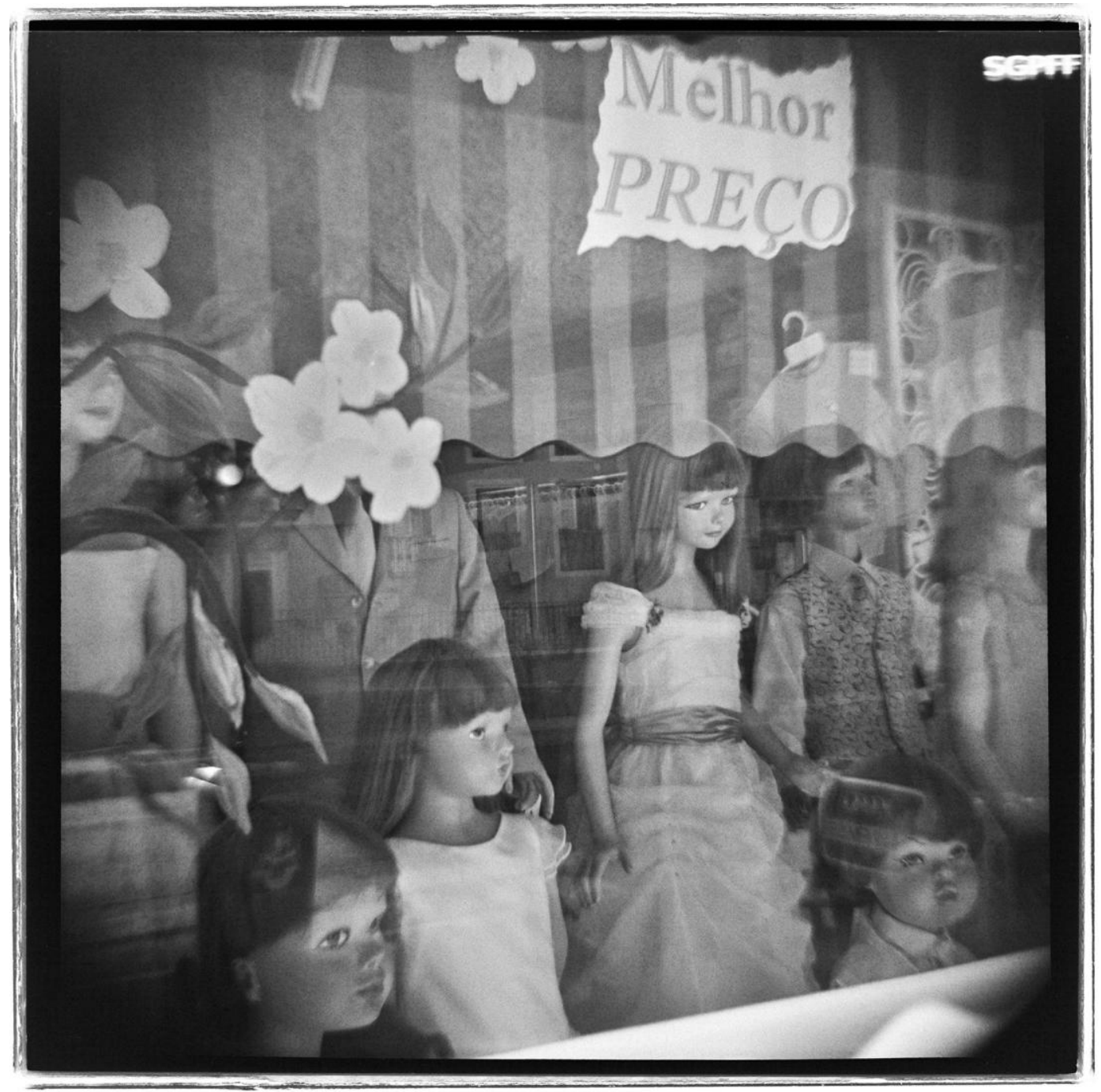

Figura 2: Imagem fotográfica exibida na exposição “Shangai”, de Lucas Cuervo, Curitiba 2014.

As fotografias da exposição Shangai denunciam a ilusão da mimese. Evidenciam o processo de captura da imagem e a interferência da máquina. Não só pelo enquadramento, pela

Iluminuras, Porto Alegre, v. 15, n. 35, p. 403-409, jan./jul. 2014 
pose ou pelo foco, mas também pela interferência sem controle do filme chinês, na captura e processamento das imagens.

Essa quebra a partir de uma ideia bem humorada contagia o espectador. O tom de brincadeira, de exploração do descontrole no processo pode ser sentido na percepção. $\mathrm{O}$ espectador pode deixar seu olhar passear pela imagem e finalmente enxergar a máquina, o outro autor. Enxergando a máquina como o outro autor, ele pode se enxergar também, porque não?

Neste processo, o espectador pode perceber a edição do fotógrafo, a escolha, o privilégio de uma imagem em detrimento de outra e pode imaginar o que acontecia ali, do lado daquela cena escolhida. Outro jogo, uma brincadeira, um prazer. Enxergar a máquina desconstrói a mimese.

A mimese foi a ideia vigente principalmente no primeiro século de existência da fotografia. A fotografia, numa analogia com o seu objeto de referência, é o espelho perfeito, um analogon do objeto real. A própria natureza técnica do processo induz a idéia da sua capacidade de imitar perfeitamente as cenas do mundo real.

Antes de mais nada, a gênese mecânica afastava a fotografia da pintura e consequentemente da arte, pois sendo um processo automático, supostamente acontecia de maneira independente da genialidade de um artista. No pensamento da mimese, a diferença estaria justamente na presença do pintor entre a imagem e o espectador, enquanto a fotografia teria uma aparente ausência do fator humano.

E assim se formava o senso comum para o espectador da fotografia, ou seja, longe da arte. O espectador da pintura tinha que decifrar a interferência do pintor para perceber a representação, enquanto que a câmera fotográfica não necessitava ser decifrada, ou seja, a gênese mecânica tornava transparente o processo de transformação do objeto em imagem.

Neste senso comum construído, a pintura ficava com o papel sensível e divino da criatividade, advinda do nobre e misterioso imaginário humano, enquanto à fotografia cabia única e exclusivamente o papel factual e "científico" da documentação ou da preservação documental do real. A crença na eficiência das leis da óptica e da química reforçava a idéia de precisão e exatidão científica na reprodução gráfica operada pela máquina fotográfica.

Criticando a posição da fotografia como mimese, Vilém Flusser (1985), pensador do século XX, diz que a mimese une a imagem e o mundo numa cadeia ininterrupta de causa e efeito, dando a sensação para o espectador de deciframento imediato. Para ele, na mimese o

Iluminuras, Porto Alegre, v. 15, n. 35, p. 403-409, jan./jul. 2014 
observador confia na fotografia tanto quanto nos seus próprios olhos, ignorando a ação tranformadora do fotógrafo e da câmera ao captar a imagem.

Shangai é um elogio à desconstrução da mimese. Suas imagens ao mesmo tempo que evidenciam a presença da câmera e do filme na mediação, proporcionam uma percepção ampliada e a construção de um "real" com a participação do espectador, aproximando a fotografia da arte definitivamente.

As fotografias do grupo Baita Profissional, em Shangai, mostram que as imagens são mediações entre o homem e o mundo. São representações e mapas deste mundo, que precisam ser decifrados, interpretados, enfim, sentidos. Mostram que as imagens fotográficas não podem somente ser consideradas como espelhos "perfeitos" do mundo, ou seja, transparentes. Elas ressaltam, escolhem, privilegiam, enfim, lêem o real, no caso de Shangai, à maneira do fotógrafo e também do filme made in China.

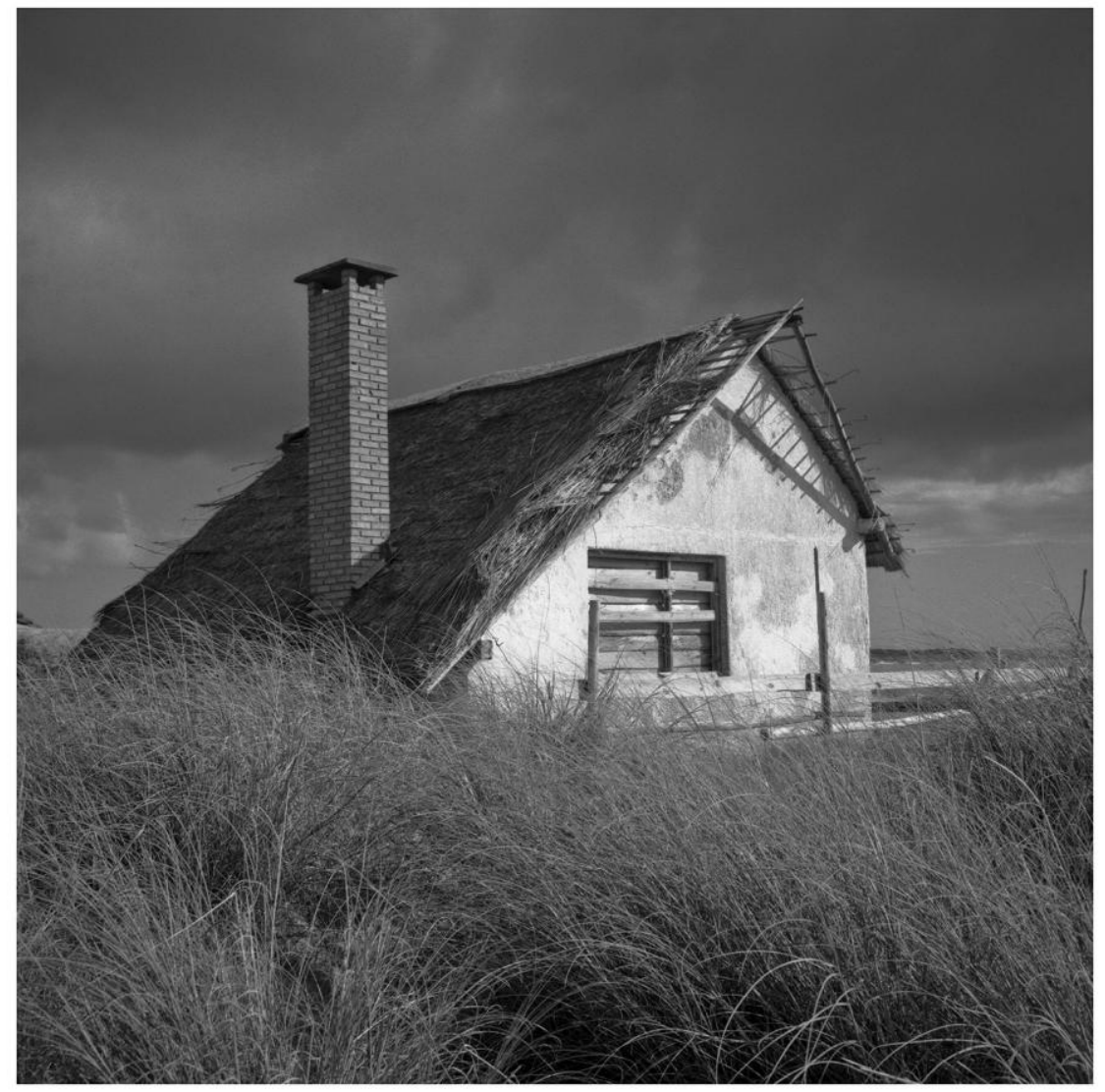

Figura 3: Imagem fotográfica exibida na exposição “Shangai”, de Anderson Astor, Curitiba 2014.

Iluminuras, Porto Alegre, v. 15, n. 35, p. 403-409, jan./jul. 2014 
O desafio está, para o fotógrafo de Shangai, em uma certa perda do controle. O que fazer se o filme pode "estragar" tudo? O fotógrafo aprendeu a capturar exatamente o que queria, aprendeu a ignorar o filme. Por um lado, se o filme é "transparente", a culpa de uma imagem não perfeita é do fotógrafo, pois este filme vai fazer exatamente o que se pede. Porém, por outro lado, se não se tem controle sobre o que o filme vai fazer, a culpa pode ser do filme, não? Em Shangai a culpa pode ser do filme.

Enfim, a imagem fotográfica não acontece por causa da automaticidade do processo de apreensão, mas apesar dela. Quando a gênese automática é mais fortemente considerada que o resultado imagético da fotografia, a sensação de mimese é mais forte. Por outro lado, quando o resultado imagético da representação do real é mais fortemente considerado pode-se uma série de "falhas" em relação à representação do real.

Essa representação precisa então ser preenchida pelo total da percepção humana. Shangai é um elogio à fotografia como meio de expressão dependente do fotógrafo, do espectador e do meio.

\section{Referências}

CAIVANO, José Luis. La Representación del Mundo Visual em la Fotografía y Post-Fotografía, In: Visio, vol. 4: (1): 37-42, 1999.

DUBOIS, Philippe. O Ato Fotográfico. Papirus, 1998.

FLUSSER, Vilém. Filosofia da Caixa Preta. Hucitec, 1985.

MACHADO, Arlindo. A Ilusão Especular. Brasiliense, 1984.

SILVEIRA, Luciana Martha. A Percepção da Cor na Fotografia em Preto e Branco. Tese de doutorado. PUC-SP. 2002.

Iluminuras, Porto Alegre, v. 15, n. 35, p. 403-409, jan./jul. 2014 